International Journal of Heritage, Tourism and Hospitality Vol. (13), No. (1), March, 2019

By: Faculty of Tourism and Hotels, Fayoum University

\title{
The Use of Global Educational Platforms in Student Assessment: An Applied Approach on Students of Higher Hospitality Education at FTH, Alexandria University \\ Dina Weheba \\ Faculty of Tourism and Hotels, Alexandria University
}

\begin{abstract}
It has always been the highest aim to focus on students and their needs, in all levels of education, giving them instant and true evaluation of their performance and helping them take corrective actions whenever needed. Academics need to focus basically on teaching and not the paper work involved. Students should feel that they are evaluated without bias, and kept informed along the course. This paper is an applied approach of using a free online educational platform as an example of a technological tool that can be implemented to help both students and academics .

The global educational networks are used to allow a complete control over the digital class, where groups of students can be created easily. Students get to participate and share, while kept informed, and evaluated. The study is giving some examples of educational platforms around the world that can be useful for both academics and students. A field study is conducted, to collect feedback from students about the whole experience of using one of these educational platforms, advantages and disadvantages. The objective of this study is to explain the importance and the possibilities created by using this global educational network, by demonstrating the steps required to join a class, meanwhile giving a glimpse on how students felt about the whole experience. Real courses are being given using similar educational platforms, and results of the approach will be given according to the students' interaction during an entire course .

The findings of this paper are very important as they represent the results of a true approach to help hospitality academics provide instant and better student evaluation along the courses, while allowing students to participate, be motivated to keep in touch with class activities at all times, and compete to perform better throughout the course.

Keywords: Hospitality students, educational platforms, student evaluation, interactive learning, student performance.
\end{abstract}

\section{Introduction}

Because of today's technology, life styles of people -especially young ones- have changed remarkably, and unlike their parents, the young have their own tastes in some areas, such as learning, playing, communicating and working. (Cankaya, et.al., 2014). Social Networking Sites (SNSs) have attracted the educators to use them in education. Thus, the use if SNSs becomes an influential educational technique. (Lave and Wenger, 1991)

SNSs such as Facebook, Google+ and MySpace, have been used intensively by students lately. Educational Social Networking Sites (ESNSs), which can also be called Learning Social Networking Sites (LSNSs), such as Edmodo, Ning, Elgg -innovative educational environments with social networking capabilities- have also been used in education. (Cankaya, et.al., 2014) In our recent world, more than a billion people are using SNSs to be in touch with their friends and others who share similar interests, as well as sharing, collaborating and contributing through their knowledge over SNSs (Cheung, et.al., 2011)

Boyd and Ellison (2007) define the SNSs as web-based services, which allow individuals to: (a) construct a public or semi-public profile within a bounded system, (b) articulate a list of other users with whom they share a connection, and (c) view and traverse their list of connections and those made by others within the system. 
The most common features and characteristics of most existing SNSs as put by Ozkan and McKenzie (2008) are:

SNSs:

- $\quad$ provide email services, instant messaging, chat, video, file and photo sharing.

- $\quad$ provide a database for users

- $\quad$ allow users to create their profiles online.

- $\quad$ are free of charge

- $\quad$ allow users to set up their own access and privacy rules.

Educational Social Networking Sites (ESNSs) -like Edmodo, Ning and Elgg- can provide educators and students with the opportunity to use social networking technologies that are content free of any inappropriate environment. (Brady et al., 2010).

\section{Related definitions}

\section{LMS (Learning Management System):}

Wu, et.al., (2010) explained that LMS are systems that provide instructors and learners with multiple, flexible educational technologies, and learning resources that are applied in interactive learning environments, to overcome the limitations of classroom and e-learning.

(a) Developers' definition

- Essel, (2017) defines it as a software application for the administration, documentation, tracking, reporting and delivery of educational courses. It stores and manages course contents and activities online.

\section{(b) Teachers' definition}

According to Essel's definition, is a virtual platform that assists in student learning, which is easy to manage and is inclusive, assessable, adaptable, transparent, safe and engaging.

Kadir \& Aziz (2016) added that LMS allows students to view multimedia lectures, communicate with their teachers and each other in the teaching communities, download course material, take online quizzes, and submit homework and assignment.

\section{Blended Learning}

Allows students to learn in online learning environments, where face-to-face and online activities are integrated in a planned, learning valuable manner where online activities replace some faceto-face time. (Kabassi, et.al., 2016)

Some examples of LMSs that are used for creating and managing the online courses are Moodle, TelEduc, BlackBoard, WebCT, Toolbook, TopClass Server and more. Amongst the main features of e-learning platforms, to students, they are considered flexible, accessible and more focused. (Lopes, 2014)

\section{Moodle}

Is an open-source learning platform that is designed to provide educators with a single strong and secured system, to create learning environments. Its main advantage is that developed courses are based on constructionist teaching. (Kabassi et.al., 2016)

MOODLE, according to Lopes, (2014) represents Modular Object-Oriented Developmental Learning, which is either known as LMS or VLE (Virtual Learning Environment). Moodle can be installed at no cost at many servers, and there are no maintenance costs needed and teachers manage the platform according to their needs. 


\section{BlackBoard}

Can be downloaded at http://www.blackboard.com, and is a learning system that provides traditional instruction and powers pure distance learning, providing special utilities such as content management and sharing, assessment and assignment gradebook. (Kabassi et.al., 2016)

\section{Edmodo (LSNSs) or (ESNSs)}

It is a Social Learning Networking System/platform that is used globally in universities and schools, and teachers serve up to communicate and transform information.

For academics, Edmodo needs them to do the following:

- Create the teacher's account on Edmodo. www.edmodo.com

- Complete the profile (as a teacher)

- Create a class or a group

- Invite students and peers to connect.

- Install Apps to engage students start activities and begin their learning process.

- Follow and communicate with other educators either from the same educational institute, or from countries all over the world, and start discovering new resources. (Essel, 2017)

\section{The Importance of the Research Problem}

Numerous reports, surveys and studies have agreed that the e-learning industry (Learning Management Systems) are increasing in number of individuals and institutions that are using it after discovering its effectiveness and its advantages. There seems to be a universal agreement that the worldwide e-learning market is showing a fast and significant growth in the very near future. (Davidovitch \& Belichenko, 2016)

\section{Methodology}

This is a descriptive analytical approach that explores the steps required to use Edmodo, as a Learning Social Networking Site (LSNS) and go through its main pros and cons, as experienced by the researcher, during teaching various courses, to different levels of students $\left(1^{\text {st }}, 3^{\text {rd }}\right.$, and $4^{\text {th }}$ grades) starting September 2017 till our present day, forming a sample of 535 students of the FTH, Alexandria University, mainly started in the hotel studies department, then the LSNS was applied in courses taught to other departments of the faculty as well.

Two online questionnaires were distributed; the first one was directed to students, to know their opinions about using this learning system, and the second one was directed to academics who were trying to apply Edmodo for the first time, after a given workshop by the researcher.

\section{Edmodo Experience}

The researcher was first introduced to Edmodo as a tool of "electronic testing and student assessment' in 2017. Getting to try Edmodo, it was found to be very good in managing the courses. Students were asked to create a free new account to be able to join classes, using a class code that was given to them once they ask to join a certain class. It was not common at first to use such educational sites, but once students signed in, it was a complete different story.

Students were asked to use clear photos of themselves when creating their profile page, which also helped in getting to know students faster and by the name very easily. Edmodo has a mobile application that can easily be downloaded on mobiles, and compatible with both iOS and Android operating systems. This application allowed students to engage easily and personalize learning for every student, by keeping in touch at all times, and being instantly notified with posts, required assignments or quizzes, and their grades ASA their work is assessed. 
Edmodo offers a powerful network, connecting students, parents, administrators and publishers. Assignments can be described in full details for students, thus avoiding the problem of having any misunderstanding or getting out-of-topic delivered assignments. Figure (1) below, shows the details of the requested assignment and the due date and time, so students know for sure when is the deadline to have assignments submitted, or face the note that shows that it was a "late submission", shown next to their grades. There is also an option to "lock" the assignment after the due time and date, so students won't be able to submit the work if being later than the deadline assigned. Edmodo made students excited about learning, as the lecturer can easily create a "blended learning" experience.

Figure 1: Assignment description and notification of due date and time

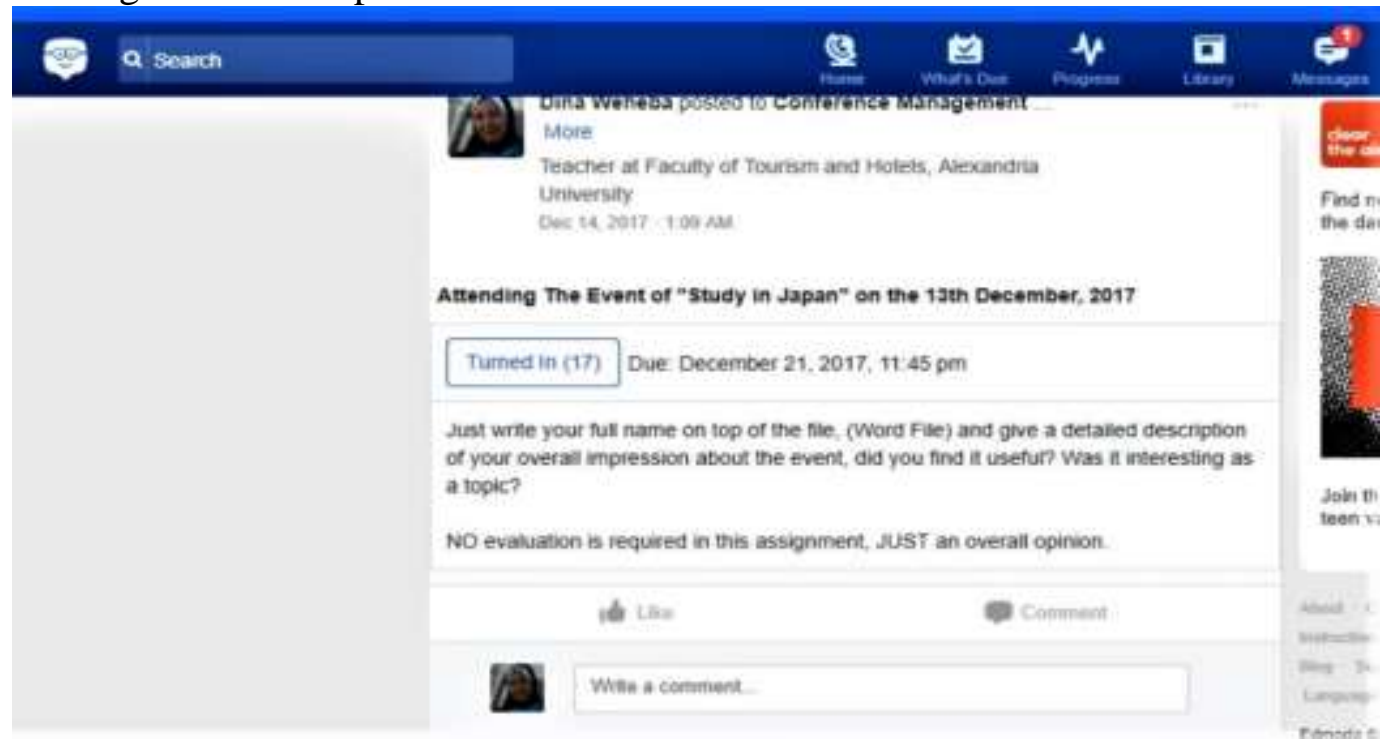

The professor has the list of "what's Due", shown in figure (2), that shows what has already been reviewed, and what assignments or quizzes are still due to come. Edmodo makes it simple to track students' progress, allowing lecturers to know the pulse of the class through assignments, quizzes, polls and much more. There is the Edmodo well-known "Online Gradebook" -explained in figure (3)- that saves a lot of time by automating the redundant tasks of inputting grades manually. There is also a "library list", in figure (4) that includes all the added files, quizzes, assignments, references for further research, lectures, and so on.

Edmodo also has many online tools that are available in the App store, including websites and contents that are easily used directly into Edmodo. 
International Journal of Heritage, Tourism and Hospitality Vol. (13), No. (1), March, 2019 By: Faculty of Tourism and Hotels, Fayoum University

Figure 2: What's due list

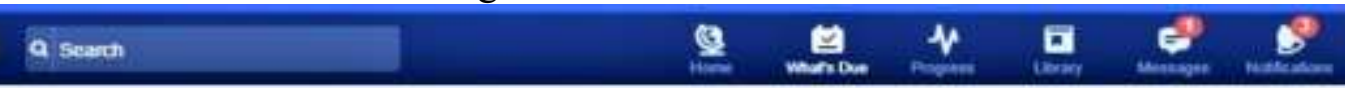

What Dot

All my classes $~-$

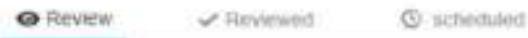

Assignener r ous Name

Reatr to Gride

Shewed

B Ranking Events Presentations on 11/10/2017

Can Deriz. 7017 , 200 ais

Evaluabing Presented Event ideas on 11/102017

fecolis an, it es re

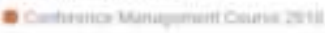

Chapter 2 Quil

chen Det so, part in wove

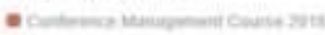

Figure 3: Edmodo's online gradebook

웅

Coeference Maragenent Couse 2018

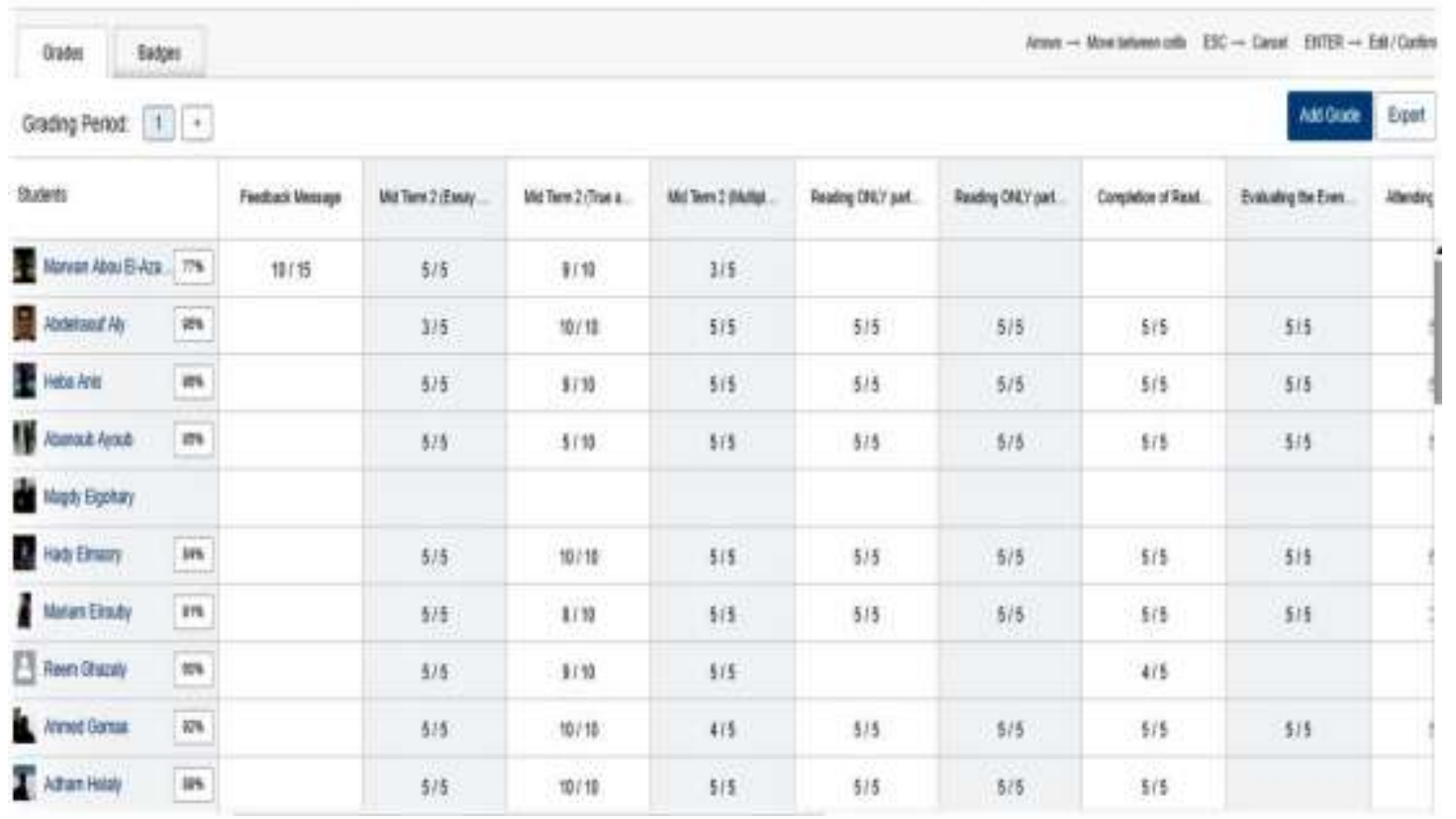


Figure 4: Teacher's Library Items

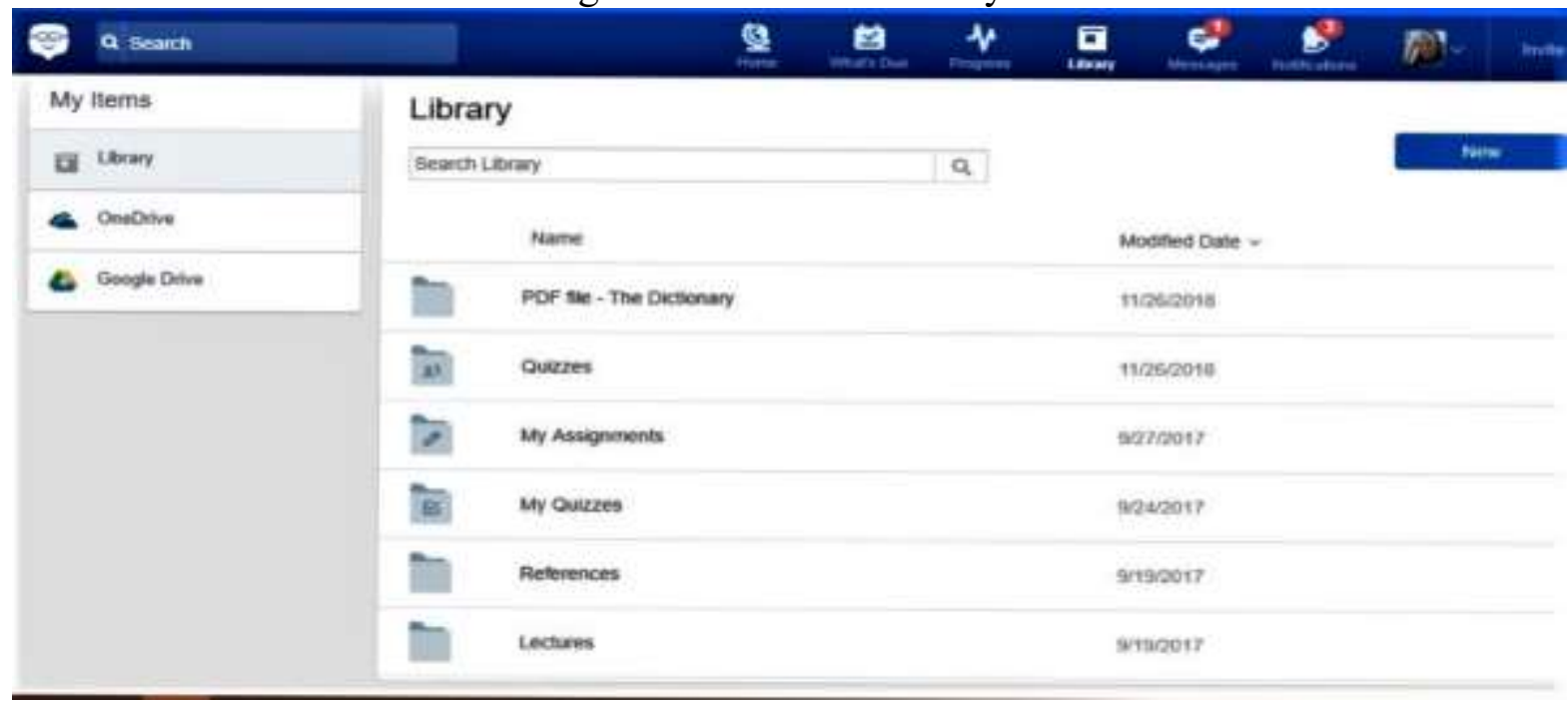

Edmodo features for the academics

1- Homepage: that includes all information of the academic in one easy-to-use interface.

2- Course profile: allowing the creating of a unique and flexible course content, also with an easy-to-use intuitive interface.

3- Edmodo planner: including and easy-to-use calendar, that allows a good management of courses and personal events, color-coded, and it offers automatic updating.

4- Creating assignments, quizzes, polls and more: Edmodo makes creating assignments easy, with simple yet detailed description of the requirements, quiz creation tools are also flexible, allowing different types of questions (multiple choice, true and false, fill in blanks, matching (that students can know their grades once they click "submit") and short answers' questions, that need the lecturer to first revise the answers and then send the assessment.

Edmodo platform has the following levels of use, (a) the administrator (manager of the platform), (b) the academic (teacher) who may also be a trainer, and (c) the student (learner) and the roles can be simplified in table (1).

Table 1: Levels and roles in Edmodo platform

\begin{tabular}{|l|l|}
\hline Role & Function \\
\hline Administrator & Manages the whole environment. \\
\hline Academic & $\begin{array}{l}\text { Generates courses, training and activities. } \\
\text { Assesses students' progress during the course. }\end{array}$ \\
\hline Student & $\begin{array}{l}\text { Has access to classes after being approved. } \\
\text { Interacts and communicates with teacher. } \\
\text { Participates in posts (comments), assignments, quizzes, polls and much more. } \\
\text { Receives grades instantly and gets notified with any updates. }\end{array}$ \\
\hline
\end{tabular}

\section{The field study and data analysis}

Students' questionnaire

The $1^{\text {st }}$ questionnaire (the multiple-questions-poll) for students, were distributed in all classes, covering a total of 535 students that were in various classes, using Edmodo. The responses were as follows: 
- A total of $83 \%$ of the students found it easy to start a new account on Edmodo, while only $17 \%$ said that it was not that easy.

Figure 5: Creating a new account on Edmodo

\section{How easy was it to create a new account on Edmodo}

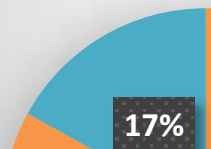

Easy to create new
account

Not that easy

$83 \%$

- Students found that Edmodo helps them be updated with all new

- Posts $(33 \%)$

- Required assignments $(61 \%)$

- Grades (6\%)

- All students (100\%) see that Edmodo kept them in touch with their professor.

- As for the use of Edmodo in various directions, the responses showed that students:

- Edmodo keeps students notified at all times (30\%)

- Edmodo allows them to get their grades instantly (15\%)

- The mobile application makes it easy to connect (10\%)

- Better communication with the professor (10\%)

- Better access to any course detail (10\%)

- And about $15 \%$ said that it gives them more than what is said above.

Figure 6: What students liked the most about Edmodo

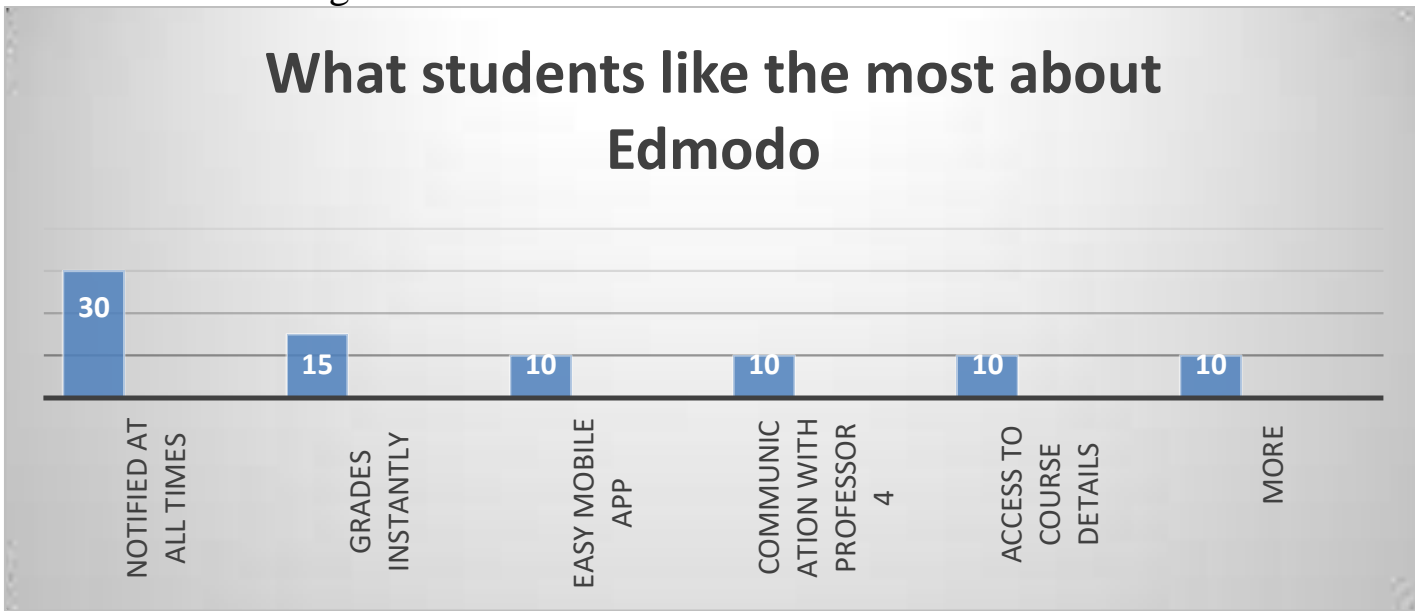

- And finally, about $63 \%$ of students found using Edmodo much fun than the traditional teaching ways. 
- Students performance has improved by using Edmodo; as students were more active and interacting in class, performing better, researching and submitting assignments within given time, and feeling that they are always connected while they get instant notifications. It made a big difference to them, and many of them sent messages thanking for allowing them the chance to try something new that appealed to them.

\section{Academics Questionnaire}

As for the academics, Edmodo was suggested to be tried for the first time, after giving one workshop, and a total number of 10 staff members have actually tried using it.

The Online questionnaire results showed the following:

- None of the academics in sample has been previously introduced to a LSNS before Edmodo.

- A total of $66.6 \%$ of academics found it extremely useful to use Edmodo, while the remaining $33.4 \%$ found it somehow useful.

- The main features that were admired when using Edmodo, were:

- Posting for students

- Detailed Assignments

- Attaching files and lectures for students

- And online quizzes

- They all liked the following facts when using Edmodo:

- Saving time

- More connection with students

- Less use of paper work

- The main obstacle they suggest facing them with Edmodo, were:

- Students were unfamiliar with this method of learning

- Students' resistance to change

- Problems of bad internet connection

- They all would recommend Edmodo and similar LSNSs to peers and other educators.

Using Edmodo, made assessing students much easier than the traditional way, with less use of paperwork, more flexibility in timing, a quizzes and tests can be answered online, so location of the exam was also more flexible, information was easier to share, with more online resources available, the experiences that students gained were more diverse and richer. For those who were keeping away from being introduced to technology, or the digital information practice, Edmodo encouraged them to get started and found it fun to learn this way.

Edmodo offered good usage of administrative tools in registration and course authorization. As students were only allowed to join classes when they get approved and receive the class code from the professor. Assessment of assignments, quizzes and tests were made easier, with a variety of types of questions and the online gradebook. Content delivery was also made faster and easier, either lectures, links or multimedia can be shared.

Edmodo's course analytics also helped analyzing test results, students scores (either individually or the whole class analysis) or on entire assessment or just analyze specific questions. This was very helpful in giving an overview about the student(s) progress in the course.

\section{Using Edmodo, Pros and Cons}

- Edmodo allows the professor to connect with other educators in the field, thus sharing similar experiences and new ideas.

- Edmodo helps to communicate in "small groups" for group work or small projects. 
- Edmodo has its own reward badges that promote students to perform better in class and in assignments requested.

- As for the cons, discovered during this study:

- Edmodo is better used in small classes, not exceeding 50 students.

- Class codes should always be locked, to avoid having students, who either fail to join, facing any slight problems in signing in, or in taking quizzes, they would try to start creating another new account, causing a big problem for the educator if not solved.

- Online quizzes can be a problem due to electricity shortage, or internet poor connectivity.

- For academics, they need a full practical training before starting to use Edmodo.

\section{Conclusion}

This paper has attempted to explore the benefits of applying (Learning Social Networking Sites) SLNSs in higher education, by knowing the students' opinions in using Edmodo in various classes, as well as exploring the responses of some academics who were being introduced to trying Edmodo for the first time. Using Edmodo has improved the professor-student communication and increased students' course content satisfaction. Edmodo also changed a lot of students' perception regarding required assignments and quizzes and how they can be submitted. Edmodo promoted students' creativity intentions and responsibility, as they were competing to submit the correct homework within the allowed time limit. The results of using Edmodo were very rewarding with students, although some implications need to be taken into consideration, such as the problems of internet connection in some areas, and the students/academics first impression of fearing to use technology in learning.

\section{The analysis of using Edmodo draws the following findings}

- Edmodo offers many good features in the learning process.

- Edmodo allows easier handling with assignments, quizzes, and the assessment process is much easier by the help of the online gradebook.

- Edmodo is better applied in smaller classes than large ones.

- Edmodo gives instant results and feedback to students, regarding their homework, which is one of the features that was highly appreciated by students.

- Edmodo is considered an open source system that allows new contributions and new applications that is making it one of the most successful sites used in learning.

- It can be concluded that using Edmodo in classes as a LSNS was very useful, and it increased students' interest to learn, participate and be more prompt in submitting their work.

\section{Recommendations}

The researcher recommends that more academics should be exposed to knowing more about LMS and LSNSs, via well-organized practical workshops, to help them and their students have a more useful learning experience, better outcome from students, and all is with much more fun.

\section{References}

A. Kadir, A. Z., \& Aziz, N.S., (2016), Learning Management System of Higher Education Institutions, Indian Journal of Science \& Technology, 9(9)

Boyd, D. M., \& Ellison, N. B., (2007), Social Network Sites: Definition, History and Scholarship, Journal of Computer-Mediated Communication, 13(1), 210-230. 
Brady, K. P., Holcomb, L. B., and Smith, B. V., (2010), The Use of Alternative Social Networking Sites in Higher Education Settings: A Case Study of the E-Learning Benefits of Ning in Education, Journal of Interactive Online Learning, 9(2), 151-170.

Cankaya, S., Durak, G., and Yunkul, E., (2014), Using Educational Social Networking Sites in Higher Education: Edmodo through the Lenses of Undergraduate Students, European Journal of Educational Technology, 1(1), 3-23.

Cheung, C. M. K., Chiu, P. Y., and Lee, M. K. O., (2011), Online Social Networks: Why do Students use Facebook? Computers in Human Behavior, (27)4, 1337-1343

Davidovitch, N., and Belichenko, M., (2016), Development and Implementation Challenges of E-Learning Management Systems in Higher Education, Canadian Center of Science and Education, 6(4)

Durak, G., (2017), Using Social Learning Networks (SLNs) in Higher Education: Edmodo through the Lenses of Academics, International Review of Research in open and Distributed Learning, Vol. 18(1)

Essel, H. B., (2017), Learning Management Systems, in Higher Education: Case of the Edmodo LMS, http://www.ResearchGate.net, accessed in February, 2017

Kabassi, k., Dragonas, I., Ntouzeivits, A., Pomonis, Tz., Papastathopoulos, G., and Vozaitis, Y., (2016), Evaluating a Learning Management System for Blended Learning in Higher Education, SpringerPlus Journal.

Lave, J., and Wnger, E., (1991), Situated Learning: Legitimate Peripheral Participation, New York: Cambridge University Press

Lopes, A. P., (2014), Learning Management Systems in Higher Education, EDULEARN Conference, Spain, PP. 5360-5365 http://www.ResearchGate.net , accessed in January, 2017

Ozkan, B., and McKenzie, B., (2008), Social Networking Tools for Teacher Education in Society for Information Technology \& Teacher Education: International Conference Chesapeake, VA:AACE, PP. 2772-2776

Wu, J. H., Tennyson, D. R., Hsia, T. L., (2010), A study of Student Satisfaction in a Blended ELearning System Environment, Computers and Education, Elsevier, 55:155-164

www.edmodo.com 